\title{
Interventional management after complicated pancreatic surgery
}

\author{
Daniel Putzer · Peter Schullian · Stefan Stättner · Florian Primavesi - Eva Braunwarth · Margot Fodor · \\ Benno Cardini - Thomas Resch · Rupert Oberhuber - Manuel Maglione - Christian Margreiter · \\ Stefan Schneeberger · Dietmar Öfner · Reto Bale · Werner Jaschke
}

Received: 5 February 2019 / Accepted: 2 April 2019 / Published online: 16 April 2019

(C) The Author(s) 2019

\begin{abstract}
Summary
Background Despite technical advances in surgical resection and postoperative management of the pancreas, surgical procedures of the pancreas are associated with a high rate of complications, resulting in a relevant morbidity and mortality. Early diagnosis and management of complications associated with pancreas surgery is mandatory, favoring a multidisciplinary approach.

Methods Interventional radiology offers minimal invasive techniques to manage post-surgical complications. These procedures are highlighted in this review, including percutaneous drainage of fluid collections, percutaneous transhepatic biliary interventions, arterial embolisation and fistula embolisation.

Results Post-surgical complications of pancreatic surgery are effectively managed by radiological procedures, offering a feasible and safe treatment with low morbidity rates. Accurate patient selection is key to an effective management of clinical situations where these interventions represent the first line approach. Conclusions Radiologic procedures allow for minimal invasive treatment of postoperative complications af-
\end{abstract}

D. Putzer $(\varangle) \cdot$ P. Schullian $\cdot$ R. Bale $\cdot$ W. Jaschke Department of Radiology, Medical University Innsbruck, Innsbruck, Austria

daniel.putzer@i-med.ac.at

S. Stättner $\cdot$ F. Primavesi $\cdot$ E. Braunwarth $\cdot$ M. Fodor . B. Cardini · T. Resch $\cdot$ R. Oberhuber $\cdot$ M. Maglione .

C. Margreiter · S. Schneeberger $\cdot$ D. Öfner

Department of Surgery, Medical University Innsbruck, Innsbruck, Austria

D. Putzer $\cdot$ P. Schullian $\cdot$ R. Bale

Microinvasive Therapy-Interventional Oncology (SIP), Department of Radiology, Medical University Innsbruck, Anichstr. 35, 6020 Innsbruck, Austria ter pancreatic surgery, reducing the time of hospitalization and the time of recovery.

Keywords Upper gastrointestinal bleeding complication - Pancreatic interventions - Percutaneous radiological treatment · Biliary interventions · Percutaneous embolization

\section{Introduction}

The technical and clinical progress in surgery of the pancreas has led to an advancement regarding resectability of pancreatic pathologies over the past decades [1]. Pancreaticoduodenectomy and total pancreatectomy are performed in a higher number of patients more effectively, with a decrease of the mortality rate to less than $5 \%$ over the past two decades in high-volume centers [2, 3]. However, these procedures are associated with a high morbidity rate and a high percentage of perioperative complications [1, 4]. The rate of postoperative complications is reported to range between 30 and $50 \%$ according to the techniques applied [5]. Relaparotomy is performed in 4 up to $20 \%$ of patients, and postoperative mortality in this patient cohort varies from 13 to $60 \%$ [6].

Post-surgical complications involve the formation of inflammatory collections, peripancreatic abscess and leakage [7-9], biliary leakage [10-16], and vascular complications $[17,18]$. Perioperative complications of the pancreas requiring surgical management are associated with an increased percentage of adverse events. The surgical treatment of postoperative complications is related to a mortality rate of nearly $2 \%$ and a morbidity of $30 \%$ [19]. Advances in interventional radiology (IR) have created clinically feasible alternatives to these surgical procedures, steadily reducing the need for resurgery [20-22]. 
IR has advanced technically over the past decades, offering minimally invasive approaches to manage surgical complications after pancreatic surgery. A classification for grading of postoperative complications in pancreatic surgery has been introduced by Clavien and Dindo [23, 24]. This grading includes five classes: Any discrepancy from the normal postoperative course without need for pharmacologic treatment or interventions is defined as grade I. Grade II complications involve pharmacological treatment. Grade III require surgical treatment, endoscopic procedures, or radiologic interventions. Grade IV are generally life-threatening and demand intensive care unit management. Grade V result in death.

Image-guided percutaneous drainage, abscess drainage, percutaneous transhepatic biliary drainage, and arterial embolization have been established as minimally invasive procedures to reduce morbidity and mortality after pancreatic surgery. These minimal invasive procedures bear the potential to improve the outcome of surgical procedures of the pancreas, and result in a shorter hospital stay and reduce the need for secondary surgical interventions [20,22].

\section{Percutaneous drainage}

Fluid collections and abscess formation in the upper abdomen are frequent complications after pancreatic surgery $[7,9]$. Postoperative pancreatic leaks and consecutive abscess formation represent a challenge in clinical management [25-31]. They occur in up to $30 \%$ of patients undergoing pancreatic resections [32]. A leak at the site of surgical resection can result in abscess formation in up to $34 \%$ of distal pancreatectomies, and is associated with the formation of subhepatic and subdiaphragmatic collections [33]. Peripancreatic fluid collections are reported to be present in up to $29 \%$ of patients after pancreatic surgery [34]. The application of surgical drains has not led to a reduction of necessary interventional radiologic procedures or surgical exploration [35]. On the contrary, image-guided percutaneous drainage has replaced surgical debridement in this setting, reducing the risk of additional morbidity and subsequent complications [36-39].

Early diagnosis and accurate management can be provided by minimally invasive interventional procedures, including image-guided percutaneous drainage. When performing percutaneous drainage, a standard evaluation of the patient is required before intervention. Patient history should be queried for allergic reactions and changes in kidney and thyroid function. Laboratory parameters to be determined before intervention are the international normalized ratio (INR), the prothrombin time, the thrombocyte count, and creatinine levels. In case of pathologic findings, appropriate countermeasures should be undertaken. Despite the fact that an absolute contraindication for percutaneous drainage of fluid collections and percutaneous transhepatic biliary drainage does not exist, a relative contraindication to be considered is inhibition of blood coagulation. If an intraabdominal abscess or fluid retention after pancreatectomy presents with a difficult-to-reach location, considerations on the treatment approach should include the feasibility of the treatment and possible complications.

Percutaneous drainage is not feasible if the pancreatic retention contains solid necrosis, as it is not drainable, and in situations where more than two repeat procedures have not led to a successful drainage of the pancreatic process [40]. In case of difficult-toreach abscess formations or retentions, the traversal of organs such as the liver or thoracic punctures can be considered [41]. If a transhepatic approach is performed, the traversal should be as short as possible, maintaining a safe distance to large blood vessels or bile ducts. Attention should be payed to the fact that the side holes of the drain are contained within the retention to prevent contamination of the liver.

Ultrasound (US) is readily available and allows for real-time monitoring during needle placement, without radiation exposure [32]. In difficult-to-reach locations and in situations with limited visibility, computed tomography (CT)-guided interventions can overcome limitations of ultrasound imaging. The pathway of the drainage should be chosen on a direct route to the fluid collection while sparing surrounding vital structures. When choosing between direct puncture, Seldinger technique, and trocar technique, the limited access to peripancreatic collections often favors the Seldinger technique, which allows for highly accurate and safe image-guided needle placement [42]. Pigtail catheters or basket drainage catheters can be used. Double-lumen sump catheters have proven to be a feasible alternative for drainage of peripancreatic fluid collections [36]. The drainage catheter is provided with a trocar needle, allowing for fast deployment of the drainage in the tissue [39]. In the Seldinger technique, the retention is first punctured to insert a small-caliber needle followed by a guidewire. The drainage is then advanced over the guidewire. This technique allows for exact placement in anatomically difficult-to-reach locations, as is the case when performing procedures in the retroperitoneal space. This technique requires more time than a direct puncture [42]. However, correct positioning of the small-caliber needle can be confirmed directly by aspiration of material or by injection of contrast media. In addition, large-bore catheters can be introduced using stiff guidewires and sequential dilation of the access route.

Zink et al. reported a success rate of $97.6 \%$ regarding puncture techniques in percutaneous drainage after pancreaticoduodenectomy [16]. Cronin et al. reported on 365 patients who were evaluated on the success rate of percutaneous image-guided placement of drainage catheters to treat peripancreatic 
fluid collections after distal pancreatectomy using the tandem trocar technique or the Seldinger technique with a mean duration of catheter drainage of 39.7 days and a technical success rate of $100 \%$ [42]. The primary clinical success rate in this cohort was $60 \%$, defined as resolution of the peripancreatic fluid collection after percutaneous drainage not necessitating further interventions. Additional surgery was only necessary in 3 patients, confirming the technique to be safe and clinically effective. In this study, the need for catheter manipulation and the chosen catheter size were significantly associated with catheter failure, which was explained by the fact that pancreatic collections were frequently viscous.

In addition, endoscopic retrograde cholangiopancreatography (ERCP)-guided stent placement has proven to be beneficial in occlusion of pancreatic leaks, avoiding an open incision or surgical drainage placement [43-45]. The endoscope is used to locate the fluid collection or pseudocyst and to identify surrounding anatomical landmarks or adjacent vital structures. A transpapillary or transmural puncture into the collection is then performed, depending on the location and on a possible communication with the pancreatic duct system. After establishing a wire access into the collection, dilatation and stent placement enable effective drainage. One study of 92 patients undergoing endoscopic drainage reported a technical success rate of $97 \%$, a mortality rate of $1 \%$, and a complication rate of $9 \%$ [46]. The therapeutic management of pancreatic leaks includes transpapillary pancreatic duct stenting in order to bridge a leak. If the pancreatic duct is disconnected, transluminal stenting is indicated [47]. However, stent migration and pancreatitis are significantly associated with stent placement [10, 48].

Major complications during drainage placement or postoperatively include hemorrhage, septic shock, enteric fistula, peritonitis, pneumothorax, and pericatheter leakage. Complication rates of up to $15 \%$ are reported in the literature [49]. In comparison, the rate of biliary leakage after surgery ranges from 0.8 to $12 \%$ [50]. Most leakages occur at the site of bilioenteric anastomosis, resulting in peritonitis, bilomas, or fistulas [51].

\section{Percutaneous transhepatic biliary procedures}

Biliary leaks can result in formation of inflammatory collections, creating the need for percutaneous transhepatic biliary drainage, which has proven to be effective [12, 52, 53]. Bile leaks are defined by the International Study Group of Liver Surgery as fluid with increased bilirubin concentration at least 3 -times greater than the serum bilirubin concentration at that time [54]. Bilioenteric reconstruction after pancreaticoduodenectomy complicates postoperative endoscopic investigation of the biliary tree. A percutaneous transhepatic approach is an alter- native to treat possible complications, performing percutaneous transhepatic cholangiography with percutaneous transhepatic biliary drainage (PTC/PTBD).

This procedure is effective in the treatment of biliary leaks, which are present in 3 to $4 \%$ of patients undergoing surgical resection $[11,16]$. Biliary leaks occur most often at the bilioenteric anastomosis, rarely at the stump of the cystic duct. Percutaneous transhepatic cholangiography is indicated if endoscopic retrograde cholangiopancreatography is not effective or surgical resections prevent endoscopic access $[55,56]$. The biliary system is punctured under US guidance, aiming at a peripheral bile duct. A 21- or 22-gauge Chiba needle is used to puncture the liver and a peripheral intrahepatic biliary duct. Following a diagnostic cholangiogram, a thin guidewire is introduced through the $22 \mathrm{G}$ needle to catheterize the biliary tree. If necessary, another biliary duct can be chosen to gain a more favorable access to reach the biliary leak. Once the intrahepatic biliary tree is catheterized, a hydrophilic guidewire is inserted into the small bowel distal to the biliary leak. A $4 \mathrm{~F}$ or $5 \mathrm{~F}$ catheter is then pushed over the guidewire into the small bowel. The flexible guidewire is then replaced by a stiffer one, in order to insert a catheter for drainage (diameter up to $12 \mathrm{~F}$ ). Catheter sideholes should be positioned proximal and distal to the anastomotic leak, in order to reduce pressure gradients. The exact positioning can be confirmed by imaging following contrast media application. Catheters can be left in place for 4 to 8 weeks [51]. In order to achieve closure of a biliary leak, long-term drainage is necessary, requiring close surveillance of the patient, fluoroscopic control of the catheter position and function, as well as multiple exchanges of drainage catheters. These measures are performed in order to avoid catheter occlusion.

Covered stents can be inserted to seal a biliary leak while providing biliary drainage. In most cases, stents of 7 to $10 \mathrm{~mm}$ diameter are appropriate. Despite considerations on the local diameter of the biliary duct, the length of the leakage and possible landing zones have to be evaluated. Self-expandable metallic stents have proven to be feasible in this indication [56]. Fully covered metal stents can be applied in this setting, especially in more complex leaks. However, long-term results are discouraging, since covered and non-covered stents may migrate or occlude within 3-6 months $[13,56]$. In patients who have undergone Whipple surgery, endoscopic access may be difficult or even impossible. Thus, an occluded stent has to be recanalized by another transhepatic procedure. Therefore, plastic, metal or covered stents should only be used in restricted cases. The technical success rate is reported to be between 65 and $90 \%$, with a complication rate between 2 and 4\%, including liver hematoma, biliary stenosis, ductal perforation, and metabolic acidosis from bile loss [55].

Biliary fistulas differ from biliary leaks, as they occur mainly if the biliary duct system is obliterated and 
gains connection to the abdominal wall and skin level, which can be the case in patients who underwent surgical drainage placement. These biliary fistulas can effectively be managed by interventional radiologic procedures. Placement of an occlusion balloon allows for obstruction of the biliary tract proximal to the fistula, and is used in combination with external drainage of the bile [57].

Surgical repair of biliary strictures leads to high morbidity and mortality rates, 28 and $2.6 \%$, respectively [58]. Percutaneous drainage and stent implantation are effective alternatives and can be repeated when required [59]. Disadvantages of stent placement include the need for stent removal to prevent inflammatory reaction and stone formation. Biodegradable stents may overcome this limitation and do not require removal [58].

\section{Venous interventions}

Involvement of the portal and mesenteric veins in malignant disease may lead to complications after pancreas surgery, especially if vascular reconstruction has been performed [60]. However venous complications after pancreatic surgery are extremely rare, and no large-scale studies are available in the literature to verify a standard treatment approach. Up to now, only case reports on postoperative venous complications after pancreatic surgery have been published [61-63]. Possible treatment approaches include direct and indirect thrombolysis, venous stenting, and mechanical thrombectomy [64]. Anastomotic stenosis after reconstruction of the portal vein is generally not feasible for endovascular treatment because of the increased risk of rupture [65].

\section{Fistula embolization}

Pancreatic fistulas are a common complication after pancreatic surgery [66]. Two large studies have reported an incidence of 9 to $29 \%[67,68]$. Despite advances in surgical techniques, the presence of pancreatic fistula resulting from an insufficiency at the site of pancreatic anastomosis is associated with a mortality of up to $10 \%$ [69].

The definition of pancreatic fistula varies in the literature, hampering an objective comparison of surgical outcome. Pancreatic fistula is defined as any measurable fluid collection with an amylase content greater than 3 times the serum amylase activity after postoperative day 3 , according to the criteria of the International Study Group on Pancreatic Fistula (ISGPF) [66]. The ISGPF defines the severity of pancreatic fistula by taking into account the impact on the clinical course of the patient. Grade A fistula are treated conservatively, and patients are asymptomatic. Grade B cases may require interventional procedures, with patients being poorly symptomatic. Grade $\mathrm{C}$ fistula may be life-threatening or require emergency surgery. Pa- tients may develop abscess, peritonitis, sepsis, and hemorrhage. These conditions occur in 10 to $30 \%$ of patients, with a mortality rate of 2 to $10 \%$ [69].

Fuks et al. evaluated 680 consecutive patients undergoing pancreatoduodenectomy for the presence of pancreatic fistula, and found three discriminant risk factors to predict grade C pancreatic fistula, including perioperative soft pancreatic parenchyma, perioperative transfusion and postoperative bleeding [70]. These risk factors were associated with a positive predictive value of $100 \%$ and a negative predictive value of $70.75 \%$, defining a high-risk group of patients.

Pancreatic fistulas often lead to fluid collections, and can be managed non-surgically in over $90 \%$ of cases [14]. Percutaneous drainage helps to evacuate the retention and to occlude the fistula. If the fistula does not heal despite long-term drainage, the communication pancreatic duct can be occluded just proximal to the leak. Catheterization of the leaking pancreatic duct can be very difficult or impossible. Thus, embolization of the fistula should be performed using coils and glues [71]. Following distal pancreatic resection, endoscopic sphincterotomy of the papilla of Vater may be performed to improve outflow of the main pancreatic duct.

\section{Hemorrhage}

Hemorrhages account for less than $10 \%$ of complications after pancreatoduodenectomy but are responsible for up to $38 \%$ of deaths [72].

Postoperative hemorrhage is defined according to the International Study Group of Pancreatic Surgery criteria [73]. The International Study Group of Pancreatic Surgery has introduced a grading scale considering hemorrhage by onset, location, and severity. Early hemorrhage occurs within $24 \mathrm{~h}$ of surgery, mainly associated with technical failures regarding the gastroduodenal artery stump [74, 75]. Early bleeding requires surgical repair of these technical failures in combination with a coagulopathy. Late hemorrhage is defined by an onset more than $24 \mathrm{~h}$ after surgery, and is associated with vascular erosion in the mesenteric vasculature and formation of a pseudoaneurysm of the gastroduodenal artery stump ([76, 77]; Fig. 1).

If patients are hemodynamically stable, CT is crucial to localize the site of bleeding. A triple-phase CT with application of iodinated contrast media is standard when evaluating a possible bleeding complication after pancreatic surgery. Multiplanar reformatting aids in planning of interventional procedures. Unenhanced images aid in differentiating beam-hardening artefacts from contrast media deposition. Sentinel bleeding has been defined as isolated bleeding from an abdominal drain after pancreatectomy, and is commonly associated with sepsis or anastomotic dehiscence, with risk of a major postpancreatectomy hemorrhage, requiring immediate evaluation and treatment [81]. Spasm and vascular irregularity can 


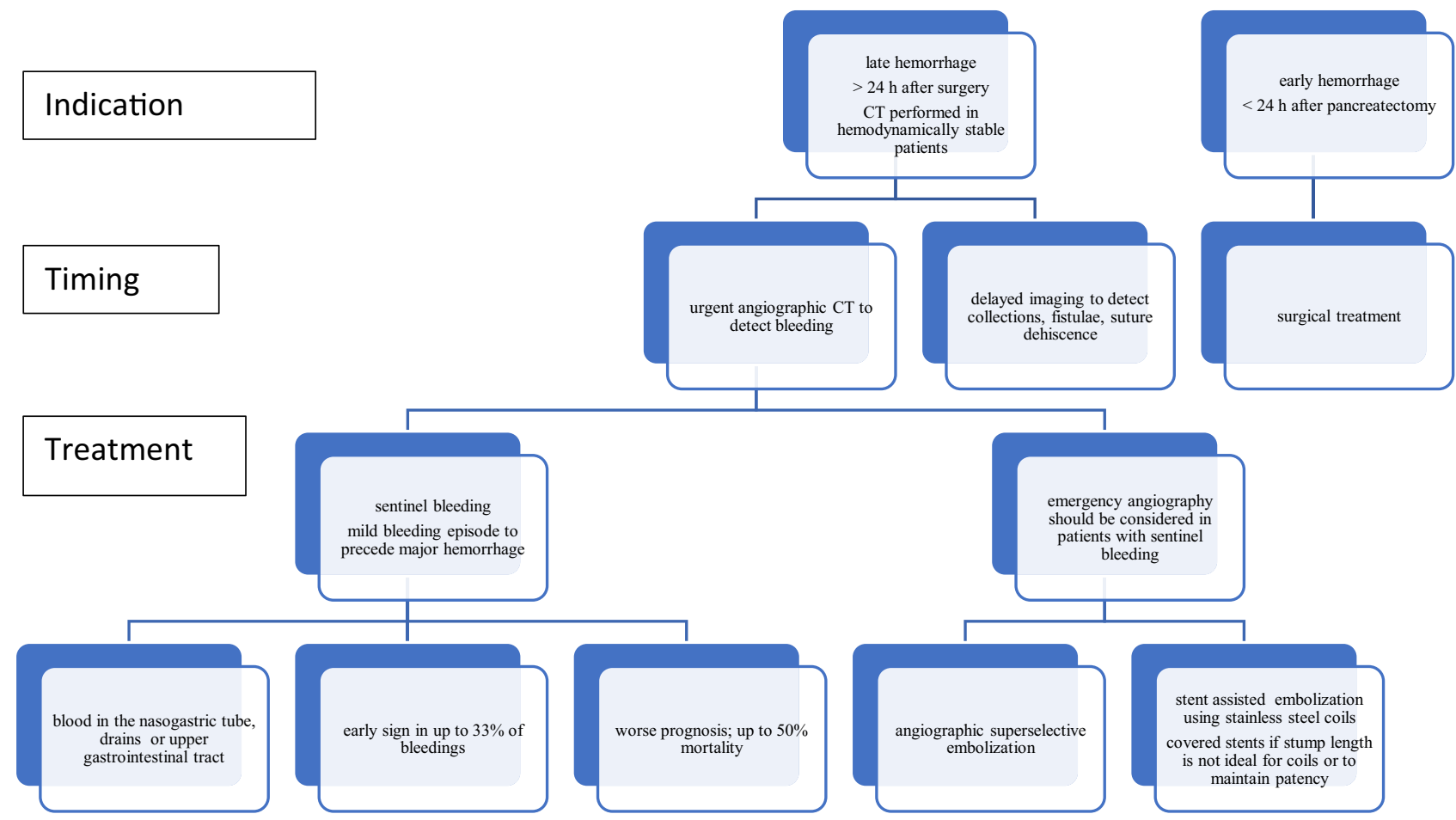

Fig. 1 Results from treatment of complicated pancreatectomy in larger cohorts confirm that early hemorrhage-defined as bleeding less than $24 \mathrm{~h}$ after surgery-should always be treated by surgery, while late hemorrhage-defined as bleeding more than $24 \mathrm{~h}$ after surgery - can be effectively treated by angiography [78]. A metanalysis on treatment of late hemorrhage found no difference between angiography and surgery regarding rate of complete hemostasis and mortality [79]. CT imaging is indicated if the hemodynamic situation is stable. Delayed CT imaging can be considered in intervals between

be indirect signs of bleeding. Selective angiography can assist in localizing the bleeding [82].

Different techniques are used to stop bleeding, including proximal embolization in order to reduce blood flow to the bleeding vessel [83]. Occlusion of the bleeding vessel at the site of bleeding results in optimal bleeding control. However, this may be impossible due to anatomic reasons. If collateral vessels feed the bleeding artery and the bleeding site cannot be catheterized, the arterial segment proximal and distal to the bleeding site has to be occluded, performing an isolation technique [84]. Permanent embolization materials should be used to control bleeding. Nonabsorbable materials include polyvinylic alcohol particles, metallic coils, and locally acting liquid embolisation materials like Onyx ${ }^{\circledR}$ (Medtronic, Minneapolis, $\mathrm{MN})$. Detachable coils are highly radiopaque and can be precisely positioned in the target vessel. However, coils require a normal blood coagulation system for vascular occlusion and cannot be delivered into very small distal arteries $(<2 \mathrm{~mm})$. PVA particles or highly viscous liquid embolization materials are better options if the blood coagulation is disturbed or the bleeding originates from arteries which cannot be bleeding episodes to detect possible causes of intermittent bleeding. In the case of sentinel bleeding, defined as a mild bleeding episode preceding a major hemorrhage, emergency angiography should be considered, as major bleedings happen in up to $33 \%$, and the mortality rate reaches $50 \%[79,80]$. In emergency angiography, coil embolization of the bleeding vessel is standard. Covered stents are used to stent across the bleeding if stump length is not ideal for coil embolization or patency of distal branches is critical, reaching a success rate of up to $79 \%$

catheterized. Distal embolization of very small arteries or capillaries using liquid embolization materials like absolute alcohol or distally acting glues should be avoided, since this may lead to tissue necrosis causing additional complications.

If the bleeding site is located in a major artery, for example the superior mesenteric or the celiac trunk, stent grafting is the best option for treatment [85]. Stent grafting preserves perfusion, but is challenging in tortuous vessels [86].

A systematic review of studies on late postpancreatectomy hemorrhages reported an incidence of 3.3\% in 7400 included patients [87]. The most frequent locations of bleedings included the abdominal cavity and the gastrointestinal tract, and sentinel bleedings were observed in $45 \%$ of the patients. The only risk factor that was identified for bleeding was the presence of pancreatic leak in $50 \%$ of patients with delayed bleeding. As bleedings with acute onset after pancreatic surgery, within 24 to $48 \mathrm{~h}$, are mainly treated surgically, endovascular treatment has its role in the management of late onset bleedings. In this systematic review, angiography was performed in 55\% of the patients with delayed bleeding, and the source 
of bleeding was localized in $88 \%$ of these, including ruptured visceral arteries, and erosion of the pancreatic stump and the enterojejunostomy. Intraluminal hemorrhage leads to hematemesis, while extraluminal bleeding presents as intraabdominal hematoma or discharge of blood from a surgical drain. While hemodynamically instable patients need to undergo laparotomy, hemodynamically stable patients should undergo CT at the time of active bleeding, in order to achieve high sensitivity.

In this systematic review, success rate of the surgical approach was $76 \%$, while interventional radiology reached $80 \%$ [87]. Corresponding mortality rates were 47 and $22 \%$, respectively. Angiography was effective in localizing the bleeding. False-negative findings could be due to the intermittent character of bleeding, and Yekebas et al. suggested repeat angiography after 6 to $24 \mathrm{~h}$ in hemodynamically stable patients to detect initially occult bleeding [88].

Endovascular complication rates in patients after pancreatectomy differ from 14 to $36 \%$ [89].

\section{Factors impacting on outcome}

No data are available on the comparison of rescue rates from different treatment approaches after complicated pancreatectomy. The studies reporting larger patient cohorts and results from longer observational periods clearly state the importance of accurate timing and fast work-up of complications after pancreatic surgery. When angiographic interventions are performed, centers with large hospital volume report better outcomes and more effective treatment, especially if interventional radiologists are available 24/7. Amrani et al. have reported that the failure-to-rescue rate depends mainly on the hospital volume and is mainly associated with renal complications (40.2\%), shock $(36.4 \%)$, cardiac complications $(35.1 \%)$, and digestive complications (33.9\%) [90]. A recent report has shown an influence of various factors on the failure-to-rescue rate after complicated pancreatectomy, including patient factors such as age, presence of ascites, and presence of malignant disease [91].

\section{Conclusion}

The multidisciplinary approach to treat post-surgical complications of the pancreas is facilitated by minimally invasive radiological procedures, shortening recovery times and reducing morbidity. Interventional radiological procedures represent the first-line treatment of post-surgical complications. The techniques have been described as feasible and safe. Radiologic procedures are equally effective yet less invasive in comparison to surgery. Patient selection and an interdisciplinary approach are the keys to successful intervention.
Funding Open access funding provided by University of Innsbruck and Medical University of Innsbruck.

Conflict of interest D. Putzer, P. Schullian, S. Stättner, F. Primavesi, E. Braunwarth, M. Fodor, B. Cardini, T. Resch, R. Oberhuber, M. Maglione, C. Margreiter, S. Schneeberger, D. Öfner, R. Bale, and W. Jaschke declare that they have no competing interests.

Open Access This article is distributed under the terms of the Creative Commons Attribution 4.0 International License (http://creativecommons.org/licenses/by/4.0/), which permits unrestricted use, distribution, and reproduction in any medium, provided you give appropriate credit to the original author(s) and the source, provide a link to the Creative Commons license, and indicate if changes were made.

\section{References}

1. Yeo CJ, Cameron JL, Sohn TA, et al. Sixhundred fifty consecutive pancreaticoduodenectomies in the 1990s: pathology, complications, and outcomes. Ann Surg. 1997;226:248-57.

2. Bentrem DJ, Yeh JJ, Brennan MF, et al. Predictors of intensive care unit admission and related outcome for patients after pancreaticoduodenec-tomy. J Gastrointest Surg. 2005;9:1307-12.

3. Fong Y, Gonen M, Rubin D, et al. Long-term survival is superior after resection for cancer in high-volume centers. Ann Surg. 2005;242:540-4.

4. Sosa JA, Bowman HM, Gordon TA, et al. Importance of hospital volume in the overall management of pancreatic cancer. Ann Surg. 1998;228:429-38.

5. Gouma DJ, van Geenen RC, van Gulik TM, et al. Rates of complications and death after pancreaticoduodenectomy: risk factors and the impact of hospital volume. Ann Surg. 2000;232:786-95.

6. Buchler MW, Wagner M, Schmied BM, Uhl W, Friess H, Z'Graggen K. Changes in morbidity after pancreatic resection: toward the end of completion pancreatectomy. Arch Surg. 2003;138(12):1310-4.

7. Casadei R, Ricci C, Giampalma E, D'Ambra M, Taffurelli G, Mosconi C, et al. Interventional radiology procedures after pancreatic resections for pancreatic and periampullary diseases. JOP. 2014;15(4):378-82.

8. Gervais DA, Fernandez-del Castillo C, O'Neill MJ, Hahn PF, Mueller PR. Complications after pancreatoduodenectomy: imaging and imaging-guided interventional procedures. Radiographics. 2001;21(3):673-90.

9. Standop J, Glowka T, Schmitz V, Schäfer N, Overhaus M, Hirner A, Kalff JC. Operative re-intervention following pancreatic head resection: indications and outcome. J GastrointestSurg. 2009;13:1503-9.

10. Cozzaglio L, Cimino M, Mauri G, et al. Percutaneous transhepatic biliary drainage and occlusion balloon in the management of duodenal stump fistula. J Gastrointest Surg. 2011;15:1977-81.

11. Cozzi G, Severini A, Civelli E, et al. Percutaneous transhepatic biliary drainage in the management of postsurgical biliary leaks in patients with nondilated intrahepatic bile ducts. Cardiovasc Intervent Radiol. 2006;29(3):380-8.

12. KimJH, Ko GY, Sung KB, etal. Bileleakfollowingliving donor liver transplantation: clinical efficacy of percutaneous transhepatic treatment. Liver Transpl. 2008;14:1142-9.

13. Mauri G, Sconfienza LM. A few thoughts on "Interventional radiology in the management of benign biliary stenoses, biliary leaks and fistulas: a pictorial review" Insights. Imaging. 2013;4(2):253. 
14. Shrikhande SV, D'Souza MA. Pancreatic fistula after pancreatectomy: evolving definitions, preventive strategies and modern management. World J Gastroenterol. 2008;14(38):5789-96.

15. Winter JM, Cameron JL, Yeo CJ, Lillemoe KD, Campbell KA, SchulickRD. Duodenojejunostomyleaks after pancreaticoduodenectomy. J Gastrointest Surg. 2008;12(2):263-9.

16. Zink SI, Soloff EV, White RR, et al. Pancreaticoduodenectomy: frequency and outcome of postoperative imaging-guided percutaneous drainage. Abdom Imaging. 2009;34(6):767-71.

17. Blanc T, Cortes A, Goere D, et al. Hemorrhage after pancreaticoduodenectomy: when is surgery still indicated? Am J Surg. 2007;194(1):3-9.

18. Limongelli $\mathrm{P}$, Khorsandi SE, Pai $\mathrm{M}$, et al. Management of delayed postoperative hemorrhage after pancreaticoduodenectomy: a meta-analysis. Arch Surg. 2008;143(10):1001-7.

19. Sohn TA, Yeo CJ, Cameron JL, et al. Resected adenocarcinoma of the pancreas-616 patients: results, outcomes, and prognostic indicators. J Gastrointest Surg. 2000;4(6):567-79.

20. Baker TA, Aaron JM, Borge M, Pierce K, Shoup M, Aranha GV. Role of interventional radiology in the management of complications after pancreaticoduodenectomy. Am J Surg. 2008;195:386-90.

21. Sanjay P, Kellner M, Tait IS. The role of interventional radiology in the management of surgical complications after pancreatoduodenectomy. HPB (Oxford). 2012;14:812-7.

22. Sohn TA, Yeo CJ, Cameron JL, Geschwind JF, Mitchell SE, Venbrux AC, Lillemoe KD. Pancreaticoduodenectomy: role of Interventional radiologists in managing patients and complications. J Gastrointest Surg. 2003;7:209-19.

23. DeOliveira M, Winter J, Schafer M, Cunningham SC, Cameron JL, et al. Assessment of complications after pancreatic surgery. A novel grading system applied to 633 patients undergoing pancreaticoduodenectomy. Ann Surg. 2006;244(6):931-7.

24. Dindo D, Demartines N, Clavien PA. Classification of surgical complications: a new proposal with evaluation in a cohort of 6336 patientsand results of a survey. Ann Surg. 2004;240:205-13.

25. Balzano G, Zerbi A, Cristallo M, Di Carlo V. The unsolved problem of fistula after left pancreatectomy: the benefit of cautious drain management. J Gastrointest Surg. 2005;9:837-42.

26. Fahy BN, Frey CF, Ho HS, Beckett L, Bold RJ. Morbidity, mortality, and technical factors of distal pancreatectomy. Am J Surg. 2002;183:237-41.

27. Goh BK, Tan YM, Chung YF, et al. Critical appraisal of 232 consecutive distal pancreatectomies with emphasis on risk factors, outcome, and management of the postoperative pancreatic fistula: a 21-year experience at a single institution. Arch Surg. 2008;143:956-65.

28. Halloran CM, Ghaneh P, Bosonnet L, Hartley MN, Sutton $\mathrm{R}$, Neoptolemos JP. Complications of pancreatic cancer resection. Dig Surg. 2002;19:138-46.

29. Munoz-Bongrand N, SauvanetA, Denys A, SibertA, Vilgrain V,Belghiti J.Conservative management of pancreatic fistula after pancreaticoduodenectomy with pancreaticogastrostomy. JAm Coll Surg. 2004;199:198-203.

30. Pannegeon V, Pessaux P, Sauvanet A, Vullierme MP, Kianmanesh R, Belghiti J. Pancreatic fistula after distal pancreatectomy: predictive risk factors and value of conservative treatment. Arch Surg. 2006;141:1071-6. discussion 1076.

31. Vin Y, Sima CS, Getrajdman GI, et al. Management and outcomes of postpancreatectomy fistula, leak, and ab- scess: results of 908 patients resected at a single institution between 2000 and 2005. JAm Coll Surg. 2008;207:490-8.

32. Kwon YM, Gerdes H, Schattner MA, Brown KT, Covey AM, Getrajdman GI, Solomon SB, et al. Management of peripancreatic fluid collections following partial pancreatectomy: acomparison of percutaneous versusEUS-guided drainage. Surg Endosc. 2013;27:2422-7.

33. Kleeff J, Diener MK, Z'graggen K, et al. Distal pancreatectomy: risk factors for surgical failure in 302 consecutive cases. Ann Surg. 2007;245:573-82.

34. Knaebel HP, Diener MK, Wente MN, et al. Systematic review and meta-analysis of technique for closure of the pancreatic remnant after distal pancreatectomy. Br J Surg. 2005;92:539-46.

35. Conlon KC, Labow D, Leung D, et al. Prospective randomized clinical trial of the value of intraperitoneal drainage after pancreatic resection. Ann Surg. 2001;234:487-93. discussion 493-494.

36. Baudin G, Chassang M, Gelsi E, Novellas S, Bernardin G, Hebuterne X, Chevallier P. CT-guided percutaneous catheter drainage of acute infectious necrotizing pancreatitis: assessment of effectiveness and safety. AJR Am J Roentgenol. 2012;199:192-9.

37. Oglevie SB, Casola G, vanSonnenberg E, D'Agostino HB, OLaoide R, Fundell L. Percutaneous abscess drainage: current applications for critically ill patients. J Intensive Care Med. 1994;9:191-206.

38. Szentes MJ, Traverso LW, Kozarek RA, Freeny PC. Invasive treatment of pancreatic fluid collections with surgical and nonsurgical methods. Am J Surg. 1991;161:600-5.

39. VanSonnenberg E, Wittich GR, Goodacre BW, Casola G, D'Agostino HB. Percutaneous abscess drainage: update. World J Surg. 2001;25:362-9.

40. Cinat ME, Wilson SE, Din AM. Determinants for successful percutaneous image-guided drainage of intra-abdominal abscess. Arch Surg. 2002;137(7):845-9.

41. Maher MM, Gervais DA, Kalra MK, Lucey B, Sahani DV, Arellano R, Hahn PF, Mueller PR. The inaccessible or undrainable abscess: how to drain it. Radiographics. 2004;24(3):717-35.

42. Cronin CG. Interventional radiology in the management of abdominal collections after distal pancreatectomy: a retrospective review. AJR Am J Roentgenol. 2011;197:241-6.

43. Brennan PM, Stefaniak T, Palmer KR, Parks RW. Endoscopic transpapillary stenting of pancreatic duct disruption. Dig Surg. 2006;23:250-4.

44. Cicek B, Parlak E, Oguz D, Disibeyaz S, Koksal AS, Sahin B. Endoscopic treatment of pancreatic fistulas. Surg Endosc. 2006;20:1706-12.

45. May K, Hunold P. Leakage of hepaticojejunal anastomosis: radiological interventional therapy. Visc Med. 2017;33:192-6.

46. Lüthen R, Jaklin P, Cohnen M. Permanent closure of a pancreatic duct leak by endoscopic coiling. Endoscopy. 2007;39(suppl 1):E21-E2.

47. Cahen D, Rauws E, Fockens P, Weverling G, Huibregtse K, Bruno M. Endoscopic drainage of pancreatic pseudocysts: long-term outcome and procedural factors associated with safe and successful treatment. Endoscopy. 2005;37(10):977-83.

48. Larsen M, Kozarek R. Management of pancreatic ductal leaks and fistulae. J Gastroenterol Hepatol. 2014;29(7): 1360-70.

49. Simmons DT, Petersen BT, Gostout CJ, Levy MJ, Topazian $\mathrm{MD}$, Baron TH. Risk of pancreatitis following endoscopically placed large-bore plastic biliary stents with and with- 
out biliary sphincterotomy for management of postoperative bileleaks. Surg Endosc. 2008;22:1459-63.

50. Lorenz J, Thomas JL. Complications of percutaneous fluid drainage. Semin Intervent Radiol. 2006;23:194-204.

51. Portugaller RH, Hausegger KA. Management of biliaryleaks. In: Mauro MA, Murphy KPJ, Thomson KR, Venbrux AC, Morgan RA, editors. Image-guided interventions. 2nd ed. Philadelphia: Elsevier Saunders; 2014. pp. 1002-7.

52. Gwon DI, Ko GY, Sung KB, Kim JH, Yoon HK. Percutaneous transhepatic treatment of postoperative bile leaks: prospective evaluation of retrievable covered stent. J Vasc Interv Radiol. 2011;22(1):75-83.

53. Thompson CM, Saad NE, Quazi RR, Darcy MD, Picus DD, Menias CO. Management of iatrogenic bile duct injuries: role of the interventional radiologist. Radiographics. 2013:33:117-34.

54. Koch M, Garden OJ, Padbury R, Rahbari NN, Adam R, Capussotti L, et al. Bile leakage after hepatobiliary and pancreatic surgery: a definition and grading of severity by the international study group of liver surgery. Surgery. 2011;149(5):680-8.

55. Hunter DW. Percutaneous biliary interventions. In: Kandarpa K, Machan L, editors. Handbook of interventional radiologic procedures. 4th ed. Philadelphia: Lippincott Williams \&Wilkins; 2011. pp.577-90.

56. Pausawasadi N, Soontornmanokul T, Rerknimitr R. Role of fully covered self-expandable metal stent for treatment of benign biliary strictures and bile leaks. Korean J Radiol. 2012;13(suppl 1):S67-S73.

57. Hatzidakis AA. Quality improvement guidelines for percutaneous transhepatic cholangiography and biliary drainage. Vienna, cardiovascular and interventional radiological society of europe. 2005. https://eu-csite-storageprod.s3.amazonaws.com/www-cirse-org/files/files/SOP/ 2005/SOP_CIRSE_2005_Percutaneous\%20Transhepatic \%20Cholangiography\%20and\%20Biliary\%20Drainage. pdf. Accessed: 05.03.2019

58. Mauri G, Michelozzi C, PorettiD, etal. Bioabsorbablebiliary stent implantation in the treatment of benign bilioplasticrefractory biliary strictures: preliminary experience. Eur Radiol. 2013;23(12):3304-10.

59. Krokidis M, Orgera G, Rossi M, Matteoli M, Hatzidakis A. Interventional radiology in the management of benign biliary stenoses, biliary leaks and fistulas: a pictorial review. Insights Imaging. 2013;4:77-84.

60. Mauri G, Monti L, Pedicini V. Interventional management of in-stentthrombosisaftersuperiormesentericveinstenting. EJVESExtra. 2011;22(3):27-9.

61. Mathias K, Bolder U, Löhlein D, Jäger H. Cardiovasc Intervent Radiol. 1993;16:313-5.

62. Ota S, Suzuki S, Motsuoka H, et al. Effect of a portal venous stent for gastrointestinal hemorrhage from jejunal varices caused by portal hypertension after pancreatoduodenectomy. J Hepatobiliary Pancreat Surg. 2005;12(1):88-92.

63. Uflacker R, Alves MA, Cantisani GG, Souza HP, Wanger J, Moraes LF. Treatment of portal vein obstruction by percutaneous transhepatic angioplasty. Baillieres Clin Gastroenterol. 1985;88(1):176-80.

64. Quarrie R, Stawicki SP. Portal vein thrombosis: What surgeons need to know. Int J Crit Illn Inj Sci. 2018;8(2):73-7.

65. Sharma AM, Zhu D, Henry Z. Protal vein thrombosis: when to treat and how? Vasc Med. 2016;21(1):61-9.

66. Bassi C, Dervenis C, Butturini G, Fingerhut A, Yeo C, Izbicki J, Neoptolemos J, et al. Post-operative pancreatic fistula: an international study group (ISGPF) definition. Surgery. 2005;138(1):8-13.
67. Winter JM, Cameron JL, Campbell KA, et al. 1423 pancreaticoduo-denectomies for pancreatic cancer: a single-institution experience. J Gastrointest Surg. 2006;10:1199-210.

68. Yeo CJ, Cameron JL, Lillemoe KD, et al. Does prophylactic octreotide decrease the rates of pancreatic fistula and other complications after pancreaticoduodenectomy? Results of a prospective randomized placebo-controlled trial. Ann Surg. 2000;232:419-29.

69. Cullen JJ, Sarr MG, Ilstrup DM. Pancreatic anastomotic leak after pancreaticoduodenectomy: incidence, significance, and management. Am J Surg. 1994;168:295-8.

70. Fuks D, Piessen G, Huet E, Tavernier M, Zerbib P, Michot F, Scotte M, Triboulet JP, Mariette C, Chiche L, Salame E, Segol P, Pruvot FR, Mauvais F, Roman H, Verhaeghe P, Regimbeau JM.Life-threatening postoperative pancreatic fistula (grade C) after pancreaticoduodenectomy: incidence, prognosis, and riskfactors. J Surg. 2009;197(6):702-9.

71. Mauri G, Sconfienza LM, Fiore B, et al. Post-surgical enteric fistula treatment with image-guided percutaneous injection of cyanoacrylic glue. Clin Radiol. 2013;68(1):59-63.

72. Wente MN, Veit JA, Bassi C, Dervenis C, FingerhutA, Gouma DJ, et al. Postpancreatectomy haemorrhage (PPH) - An International Study Group of Pancreatic Surgery (ISGPS) definition. Surgery. 2007;142(1):20-5.

73. Puppala S, Patel J, McPherson S, Nicholson A, Kessel D. Hemorrhagic complications after whipple surgery: imaging and radiologic intervention. AJR Am J Roentgenol. 2011;196:192-7.

74. Kessel D. Hemorrhagic complications after Whipple surgery. AJR Am J Roentgenol. 2011;196:192-7.

75. Limongelli P, Khorsandi SE, Pai M, et al. Management of delayed postoperative hemorrhage after pancreaticoduodenectomy: a meta-analysis. Arch Surg. 2008;143:1001-7.

76. LeeHG, Heo JS, ChoiSH, Choi DW. Management of bleeding from pseudoaneurysms following pancreaticoduodenectomy. World J Gastroenterol. 2010;16(10):1239-44.

77. Otah E, Cushin BJ, Rozenblit GN, Neff R, Otah KE, Cooperman AM. Visceral artery pseudoaneurysms following pancreaticoduodenectomy. Arch Surg. 2002;137:55-9.

78. Camilo Correa-Gallego, Brennan MF, D'Angelica MI, DeMatteo RP, Yuman Fong, Kingham TP, Jarnagin WR, Allen PJ. Contemporary experience with postpancreatectomy hemorrhage: results of 1,122 patients resected between 2006 and 2011. JAm Coll Surg. 2012;215:616-21.

79. Limongelli P, Khorsandi SE, Pai M, Jackson JE, TaitP, Tierris J, Habib NA, Williamson RC, Jiao LR. Management of delayed postoperative hemorrhage after pancreaticoduodenectomy: a meta-analysis. Arch Surg. 2008;143(10):1001-7.

80. Brodsky JT, Turnbull AD. Arterial hemorrhage after pancreatoduodenectomy. The 'sentinel bleed'. Arch Surg. 1991;126(8):1037-40.

81. Tsirlis T, Vasiliades G, Koliopanos A, et al. Pancreatic leak related hemorrhage following pancreaticoduodenectomy a case series. JOP. 2009;10:492-5.

82. Makowiec F, Riediger H, Euringer W, Uhl M, Hopt UT, Adam U. Management of delayed visceral arterial bleeding after pancreatic head resection. J Gastrointest Surg. 2005;9:1293-9.

83. Miura F, Asano T, Amano H, et al. Management of postoperative arterial haemorrhage after pancreatobiliary surgery according to the site of bleeding: re-laparotomy or interventional radiology. J Hepatobiliary Pancreat Surg. 2009;16(1):56-63.

84. Rossi UG, Seitun S, Ferro C. Endovascular embolization of a third jejunal artery aneurysm: isolation techinique using the Amplatzer vascular plug 4. Catheter Cardiovasc Interv. 2013;81(6):1049-52. 
85. Sconfienza LM, Mauri G. Interventional options to treat postoperative duodenal stump leaks. Cardiovasc Intervent Radiol. 2014; https://doi.org/10.1007/s00270-014-0937-7.

86. Asai K, Watanabe M, Kusachi S, Matsukiyo H, Saito T, Kodama H, Enomoto T, et al. Successful treatment of a common hepatic artery pseudoaneurysm using a coronary covered stentfollowing pancreatoduodenectomy: report of a case. Surg Today. 2014;44(1):160-5.

87. Didier Roulin D, Cerantola Y, Demartines N, Schäfer M. Systematic review of delayed postoperative hemorrhage after pancreatic resection. J Gastrointest Surg. 2011;15:1055-62.

88. Yekebas EF, Wolfram L, Cataldegirmen G, Habermann CR, Bogoevski D, Koenig AM, Kaifi J, Schurr PG, Bubenheim M, Nolte-Ernsting C, Adam G, Izbicki JR. Postpancreatectomy hemorrhage: diagnosis and treatment: an analysis in 1669 consecutive pancreatic resections. Ann Surg. 2007;246:269-80.
89. Roulin D, Cerantola Y, Demartines N, Schäfer M. Systematic review of delayed postoperative haemorrhage after pancreatic resection. J Gastrointest Surg. 2011;15:1055-62.

90. El Amrani M, Clement G, Lenne X, Farges O, Delpero JR, Theis D, Pruvot FR, Truant S. Failure-to-rescue in patients undergoing pancreatectomy: is hospital volume a standard for quality improvement programs? Nationwide analysis of 12,333 patients. Ann Surg. 2018;268(5):799-807.

91. Varley PR, Geller DA, Tsung A. Factors influencing failure to rescue after pancreaticoduodenectomy: a National Surgical Quality Improvement Project Perspective. J Surg Res. 2017;214:131-9.

Publisher's Note Springer Nature remains neutral with regard to jurisdictional claims in published maps and institutional affiliations. 